\title{
Editorial Comments-Survey of the Bam Earthquake Survivors' Opinions on Medical and Health System Services
}

\author{
Takashi Ukai, $\mathrm{MD}, \mathrm{PhD}$
}

Senior Consultant, Hyogo Emergency

Medical Center; Chairman, Humanitarian

Medical Assistance, Hyogo, Japan

\section{Correspondence: \\ E-mail: ukai-t@mxr.mesh.ne.jp}

Web publication: 20 June 2008
Compared to the assessment reports on disaster medical response from the view point of care providers, those from the eyes of casualties are very rare. In this regard, the article by Dr. Saghafi et al on the survey of disaster survivors' opinions on medical services is particularly precious and interesting.

The Bam earthquake certainly was one of the most devastating disasters that ever has occurred in the modern world; not only in the number of deaths and its ratio to the affected population, but also in the extent of damage to the medical facilities. About one-third of the total population was killed and all three hospitals in the city and most of the urban health centers/rural health houses were severely damaged. Therefore, relief medial teams from outside of Bam were necessary for the care of casualties, as well as the aero-evacuation of the injured from Bam to unaffected cities. The number of patients transferred by airplanes and helicopters was amazing (at least 5,511 in nine days, as was cited by the same author in a different paper, and in a total of 11,792 , as was written in this paper). So, it was quite reasonable that the respondents to the questionnaire selected aero-evacuation services as the most valuable category of medical services among those they received. Excellent staging care efforts at Kerman airport also was witnessed by the commentator.

In general, international rescue and medical relief services after disasters are controversial because of their late arrival, mismatch the real needs with the affected society, duplication of services, and language and cultural barriers. But the survivors of the Bam earthquake selected international relief efforts as the second most valuable service during the disaster. Some of the above mentioned problems also were there at the time of Bam earthquake. However, the seriousness of damage to the existing medical services system in Bam outstripped the disadvantages of international relief. That must be why international assistance received the second highest score from the respondents. However, the outstanding efforts of the UNDAC, Iranian Red Crescent, and other assistance teams from Iranian cities should not be underestimated. As the damage to the local government also was so extensive, the city of Bam was divided into 14 zones. Each zone was transiently put under the government of different Iranian provinces and major cities. This strategy sounded quite sensible and actually was effective in some part of emergency response. However, due to the insufficient communication and control among the ruling provinces and central government, disparity of social services in different zones occurred, and it must have frustrated the survivors during the reconstruction period. As the authors noted, immediate aero-evacuation of the injured victims provided by relief missions by experienced and fully equipped international/domestic teams would be of great help to the victims of future disasters, if they were coordinated properly. 